\title{
Deletion of Irs2 causes reduced kidney size in mice: role for inhibition of GSK3 $\beta$ ?
}

\author{
Rosemarie M Carew ${ }^{1}$, Marianna Sadagurski ${ }^{4}$, Roel Goldschmeding ${ }^{5}$, Finian Martin² ${ }^{2}$ Morris F White ${ }^{4}$ and \\ Derek P Brazil*3
}

\begin{abstract}
Background: Male Irs2-- mice develop fatal type 2 diabetes at 13-14 weeks. Defects in neuronal proliferation, pituitary development and photoreceptor cell survival manifest in Irs $2^{-1}$ mice. We identify retarded renal growth in male and female Irs2 $\%$ mice, independent of diabetes.

Results: Kidney size and kidney:body weight ratio were reduced by approximately 20\% in $/ \mathrm{rs} 2^{-1-}$ mice at postnatal day 5 and was maintained in maturity. Reduced glomerular number but similar glomerular density was detected in Irs2 $2^{-1}$ kidney compared to wild-type, suggesting intact global kidney structure. Analysis of insulin signalling revealed renalspecific upregulation of PKB $\beta / A k t 2$, hyperphosphorylation of GSK3 $\beta$ and concomitant accumulation of $\beta$-catenin in Irs2-- kidney. Despite this, no significant upregulation of $\beta$-catenin targets was detected. Kidney-specific increases in Yes-associated protein (YAP), a key driver of organ size were also detected in the absence of Irs2. YAP phosphorylation on its inhibitory site Ser127 was also increased, with no change in the levels of YAP-regulated genes, suggesting that overall YAP activity was not increased in $1 / \mathrm{rs}^{-1 /}$ kidney.

Conclusions: In summary, deletion of Irs2 causes reduced kidney size early in mouse development. Compensatory mechanisms such as increased $\beta$-catenin and YAP levels failed to overcome this developmental defect. These data point to Irs2 as an important novel mediator of kidney size.
\end{abstract}

\section{Background}

The insulin receptor substrate (IRS) family of proteins plays a key role in insulin signalling [1]. Most, if not all, insulin signals are modulated through tyrosine phosphorylation of IRS proteins [2]. IRS proteins are intermediate cellular scaffold proteins, which act as an interface between tyrosine kinase receptors and effector proteins such as PI3K and MAPK. The crucial role of IRS proteins in insulin action has been demonstrated using knockout mouse models [3]. The distinct phenotypes of $\operatorname{Irs} 1^{-1-}$ and Irs $2^{-/}$mice present a fascinating physiological contrast, despite the significant structural similarities of these proteins [4]. Irs $1^{-/}$mice are approximately 50\% smaller in size compared to littermate controls, highlighting the importance of IRS1 in somatic growth promotion [5-7]. Irs $1^{-1-}$ mice are insulin resistant but also maintain normal

*Correspondence: d.brazil@qub.ac.uk

${ }^{3}$ Centre for Vision and Vascular Science, School of Medicine, Dentistry and Biomedical Science, Queen's University Belfast, Belfast BT12 6BA, Northern Ireland, UK

Full list of author information is available at the end of the article fasting glucose and glucose tolerance due to compensatory $\beta$-cell hyperplasia $[5,6]$. In contrast, mice lacking Irs 2 develop type 2 diabetes, with $\operatorname{Irs} 2^{-/}$male mice displaying both insulin resistance and $\beta$-cell failure at an early age $[8,9]$. In light of their pivotal role in insulin signalling, IRS proteins have been examined as candidate genes for type 2 diabetes and other human metabolic disorders [1].

Animal and organ size is determined by hormones and growth factors that control processes such as cell number, cell size and cell death during fetal development and postnatal growth [10-12]. The important role of the insulin/IGF-1 signalling pathway in growth and development is well established. Ablation of insulin and IGF-1 receptors results in early postnatal death [13-15]. IRS2 does not regulate somatic growth to the same extent as IRS1, and $I r s 2^{-1-}$ mice were only $10 \%$ smaller in size compared to wild-type controls [7]. However, Irs 2 gene deletion precipitates a number of pathophysiological effects in organs that are typically affected by diabetic complications. In the retina, Irs 2 deletion in mice caused increased 
photoreceptor cell apoptosis, with decreased maturation and survival of photoreceptors [16]. Irs $2^{-/-}$mice also display reduced neuronal proliferation, leading to reduced brain size [17]. In the kidney, insulin is known to modify several functions of renal tubules [18-23], with IRS2 playing a major role in insulin stimulation of renal proximal tubular transport and $\mathrm{PKB} /$ Akt phosphorylation in vitro [24]. Since insulin-like, and other growth factor signalling is crucial in organ development [25], we examined the effect of Irs 2 gene deletion on kidney function and development in mice. Our data highlight a novel role for IRS2 signalling in kidney size development and insulin signalling in renal cells.

\section{Results}

\section{IRS2 is expressed in mouse kidney}

Levels of IRS2 mRNA were high in mouse kidney compared to mouse liver (Fig. 1A, B). IRS2 protein was detected in wild-type and Irs2 ${ }^{+/-}$kidney, but not in Irs2 $2^{-1-}$ kidney extracts (Fig. 1C). A modest 2 -fold increase in IRS1 mRNA levels was detected in Irs2 $2^{-/}$kidney, suggesting a mild compensatory increase in IRS1 in the absence of IRS2 (Additional File 1 Fig. S1).

\section{Deletion of Irs2 causes decreased kidney size in mice}

Both kidney weight and kidney-to-body weight ratio were reduced in $\operatorname{Irs} 2^{--}$mice at 5-6 wk of age, in both male and female mice (Fig. 2 and Additional File 1 Table S1). Kidney size was clearly smaller in Irs2-/- mice compared to

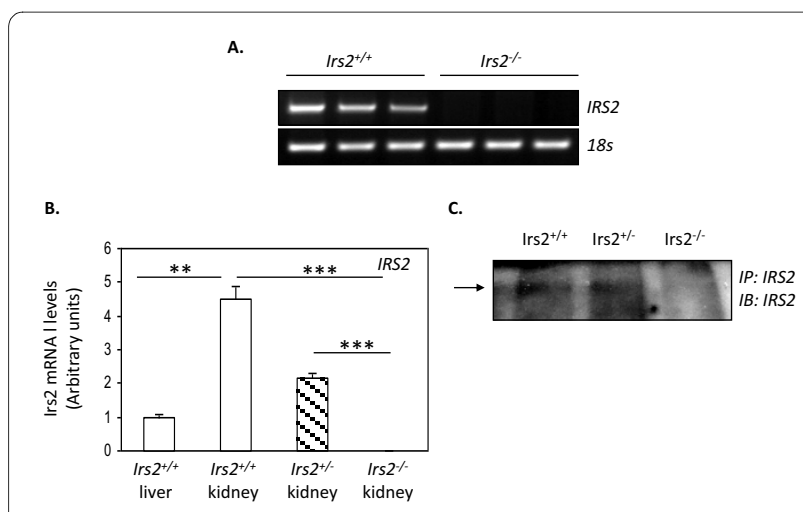

Figure 1 IRS2 is detected in mammalian kidney. Semi-quantitative (A) and quantitative TaqMan (B) PCR was performed using RNA from renal poles of 5-6 wk Irs $2^{+/+}$(empty bars), Irs $2^{+/-}$(striped bars) and Irs $2^{-1}$ mice (filled bars) and Irs 2 specific oligonucleotides as described in Material and Methods. $\triangle \Delta C t$ values were calculated by subtracting the $\mathrm{Ct}$ values for IRS2 by those for the $18 \mathrm{~S}$ control performed simultaneously, and fold change was then calculated by setting the wild-type liver group value to 1. Data are expressed as mean $+/-\mathrm{SEM}, \mathrm{n}=5$ for each group. Statistical significance was determined using one way ANOVA with post hoc Tukey-Kramer multiple comparisons test, ${ }^{* * *} p<0.001$. (C) Immunoprecipitation was carried out on $1 \mathrm{mg}$ protein lysates from Irs2 $2^{+/+}$, Irs2 $2^{+-}$and Irs2-/- kidney. Protein lysates were separated on $7.5 \%$ SDS-PAGE and probed by Western blotting with anti-IRS2 antibody.

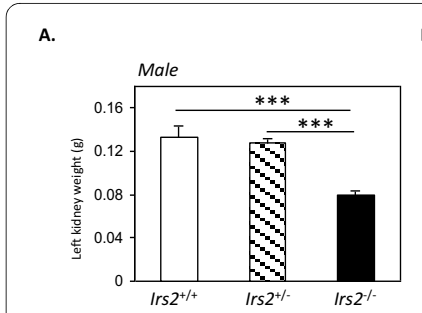

C.
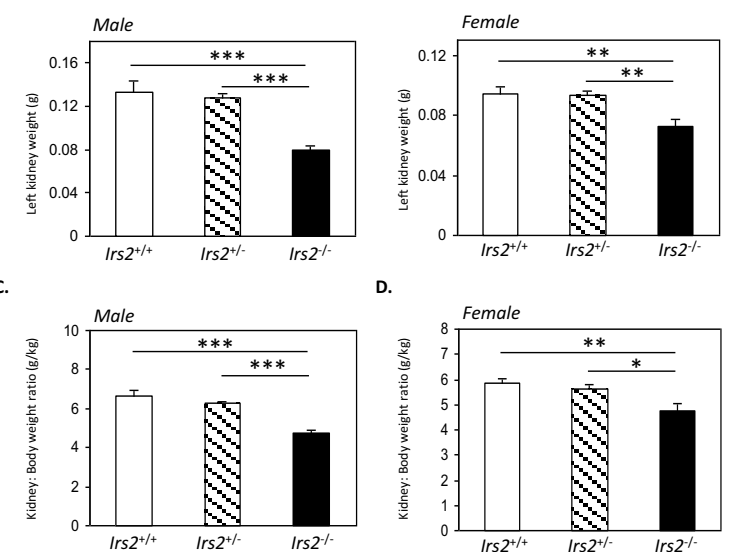

Figure 2 Irs2 gene deletion significantly decreases kidney-tobody weight ratio. Left kidney weights of 5-6 wk old (A) male and (B) female Irs2 $2^{+/+}$(open bars), Irs $2^{+/-}$(hatched bars) and Irs2 ${ }^{-1-}$ (filled bars) mice were measured at the time of sacrifice. Kidney-to-body weight ratios were calculated for (C) male and (D) female groups and expressed as $\mathrm{g} / \mathrm{kg}$. Data were plotted as mean $+/$ - SEM ( $\mathrm{n}=7-8$ for each group).

wild-type at various time-points (Fig. 3A, B and Additional File 1 Fig. S2). Newborn Irs $2^{-/}$mice displayed a reduction in kidney-to-body weight ratio at $5 \mathrm{~d}$ of age (wild-type $5.411+/-0.115$, Irs2-/- $4.364+/-0.2, p<0.001$ ) which was maintained up to $25 \mathrm{~d}$ and beyond (Fig. 3C). The slopes of the growth curves indicated that $\mathrm{Irs} 2^{-/-}$mice had a higher rate of growth between $5 \mathrm{~d}$ and $12 \mathrm{~d}$ com-

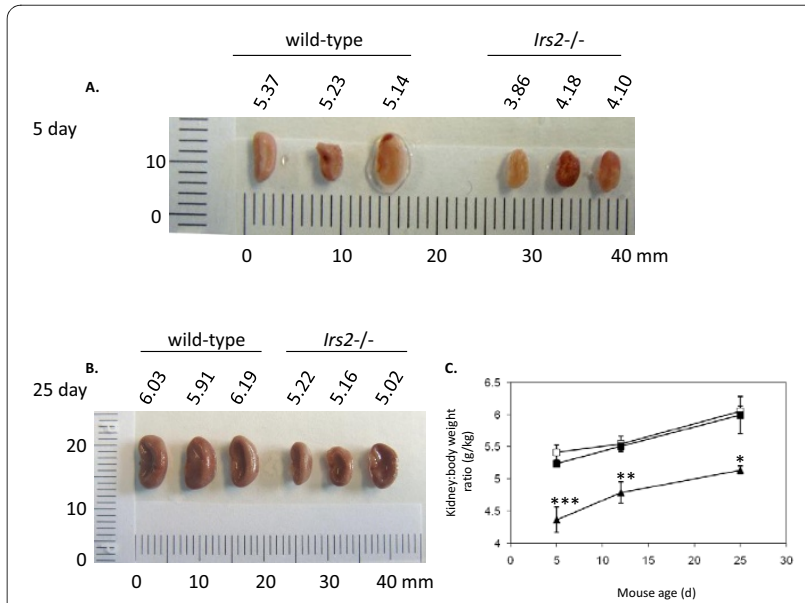

Figure 3 Kidney size is reduced at early postnatal timepoints in Irs2-/- mice. Kidneys $(\mathrm{n}=3$ ) from (A) $5 \mathrm{~d}$ and (B) $25 \mathrm{~d}$ wild-type and Irs2/- male and female mice were removed upon sacrifice and photographed as described. Size in $\mathrm{mm}$ is shown for scale. (C) Left kidney-tobody weight ratios were calculated for Irs $2^{+/+}$(open squares), Irs $2^{+/-}$ (filled squares) and Irs2--(filled triangles) mice at $5 \mathrm{~d}, 12 \mathrm{~d}$ and $25 \mathrm{~d}$ male and female mice combined and expressed as $\mathrm{g} / \mathrm{kg}$. Data were plotted as mean $+/$ - SEM, $n=3-5$ for each group. Statistical significance was determined using one-way ANOVA and Tukey-Kramer multiple comparison test, ${ }^{*} p<0.05,{ }^{* *} p<0.01,{ }^{* * *} p<0.001$. 
pared to wild-type or Irs2 $2^{+-}\left(\right.$Irs2 $2^{+/+}$slope 0.0189, Irs2 $2^{-/}$ slope 0.0605). However, the growth rate was similar between $12 \mathrm{~d}$ and $25 \mathrm{~d}$ in all three genotypes, suggesting that this higher rate of growth was not maintained in Irs21 - mice. Supporting this observation, kidney size in older female mice (43-44 wk) remained smaller in Irs $2^{-/-}$mice compared to wild-type (data not shown), suggesting that the initial defect in kidney growth is not overcome during the lifetime of the Irs $2^{-1-}$ mouse. No significant histological changes were seen in Irs2 ${ }^{-/}$kidneys compared to wildtype at any age group, using a range of specific stains for markers of kidney damage (Additional File 1 Fig. S3). Quantitation of glomeruli in H\&E stained paraffin sections revealed that $\operatorname{Irs} 2^{-1-k i d n e y s}$ contained less glomeruli per kidney section than wild-type (Irs2-/- 200+/- 29 glomeruli per section, wild-type $217+/-25$ glomeruli per section). However, when normalised for sectional area, a similar density of glomeruli (and by inference, nephrons) was present in Irs2-/- kidneys compared to wild-type mice (Additional File 1 Fig. S4). Together, these data suggest that Irs2 deletion leads to a global reduction in mouse kidney size during development.

\section{Irs2 deletion causes increased PKB/Akt signalling specifically in kidney}

$\mathrm{PKB} /$ Akt activation is a key regulator of glomerular podocyte and tubular epithelial cell survival [26-29]. The status of $\mathrm{PKB} /$ Akt expression was therefore assessed in kidneys of wild-type, Irs2+/- and Irs2-/- kidneys. Surprisingly, levels of total PKB/Akt were elevated in both male and female Irs2-/- kidneys at 5-6 wk of age compared to wild-type and Irs2+- (Fig. 4). This 2.5-3-fold increase in $\mathrm{PKB} /$ Akt expression was also maintained in older mice (data not shown). Using isoform specific antibodies, marked upregulation of PKB $\beta /$ Akt2 was identified in Irs2-

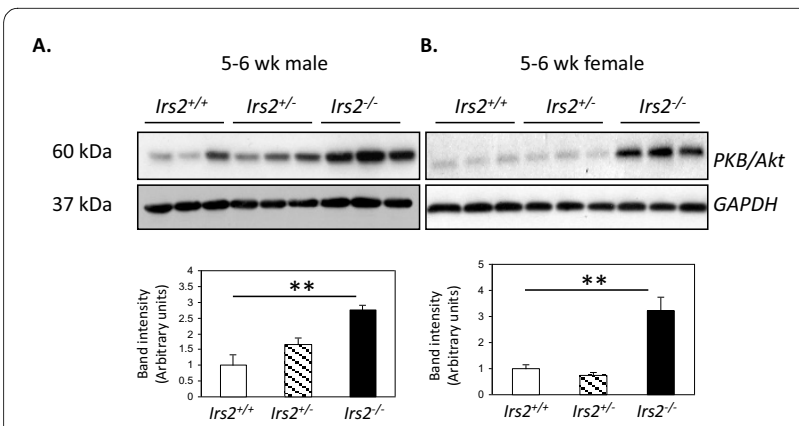

Figure 4 Increased PKB/Akt expression in Irs2 ${ }^{-/-}$mouse kidney Twenty $\mu \mathrm{g}$ of kidney protein lysates from 5-6 wk Irs $2^{+/+}$, Irs $2^{+/-}$and Irs21-5-6 wk male (A) and female (B) groups were separated on 10\% SDSPAGE and probed by Western blotting with anti-PKB/Akt. GAPDH was used as a loading control. Band intensities were calculated using Scion Image software. The intensity ratios of PKB/GAPDH are shown. ${ }^{*} p<$ 0.01

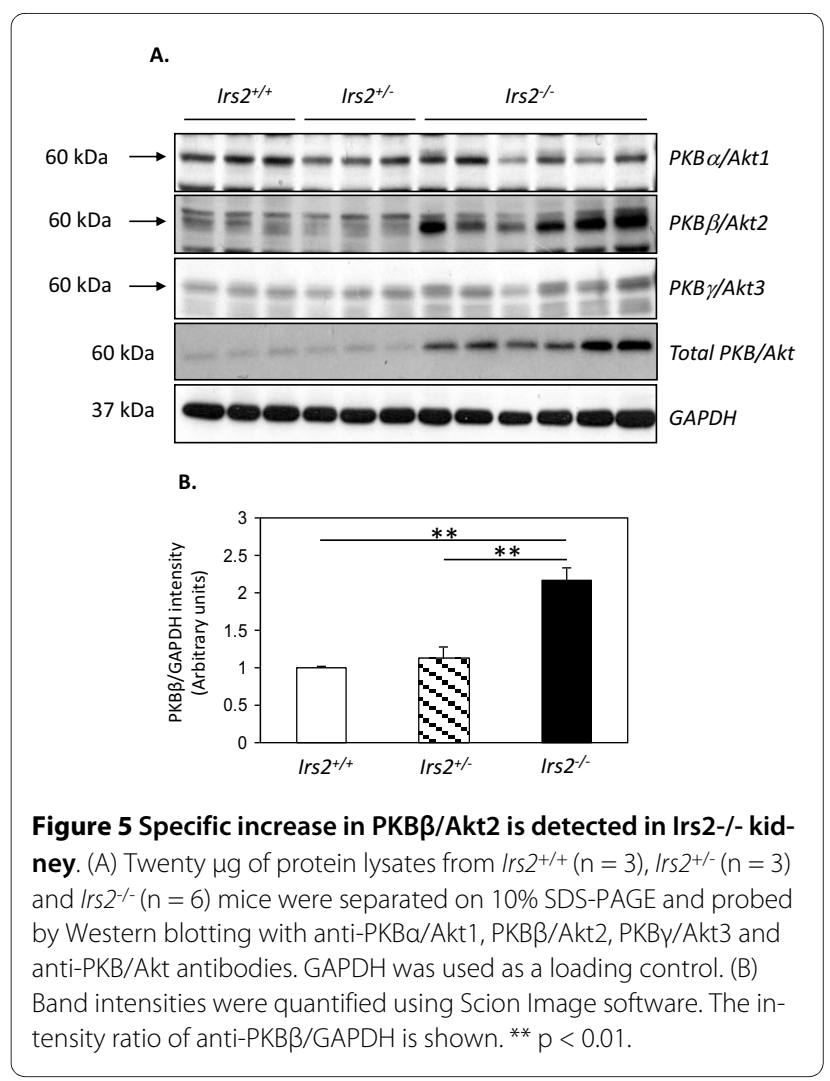

I- mouse kidney compared to controls (Fig. 5). This increase was not observed in Irs $2^{-/}$liver or brain (data not shown), suggesting that upregulation of PKB $\beta / A k t 2$ may be specific to Irs $2^{-\%}$ mouse kidney. No change in the level of mRNA for all three PKB/Akt isoforms was detected in Irs $2^{-/-}$kidney compared to wild-type or Irs $2^{+/}$, suggesting that either increased PKB $\beta /$ Akt2 translation or post-transcriptional stability may account for the observed protein increase in kidney in the absence of Irs 2 .

To explore whether defects in growth factor signalling contribute to decreased kidney size in Irs2-/- mice, the activation of $\mathrm{PKB} /$ Akt in kidney in response to insulin was assessed. Insulin stimulated PKB/Akt phosphorylation in both wild-type and Irs2-- kidney (Fig. 6A-C). Levels of basal PKB/Akt Thr308 and Ser473 phosphorylation also appeared to be higher in Irs2 ${ }^{-1-}$ kidney compared to wild-type (Fig. 6). Insulin injection triggered a higher degree of PKB/Akt phosphorylation on Thr308 in Irs2 ${ }^{-1}$ kidney compared to wild-type, whereas fold-change of Ser473 phosphorylation was similar between the two genotypes (Fig. 6). These data suggest that PKB/Akt activation may be increased in the absence of IRS2 in kidney.

The effect of increased PKB $\beta /$ Akt2 expression on the phosphorylation of GSK3 $\beta$, a major downstream target of PKB/Akt was then assessed. Phosphorylation of GSK3 $\beta$ on the inhibitory Ser9 site increased in both wild-type and Irs2 $2_{-1}^{-}$kidney in response to insulin (Fig. 7A). How- 


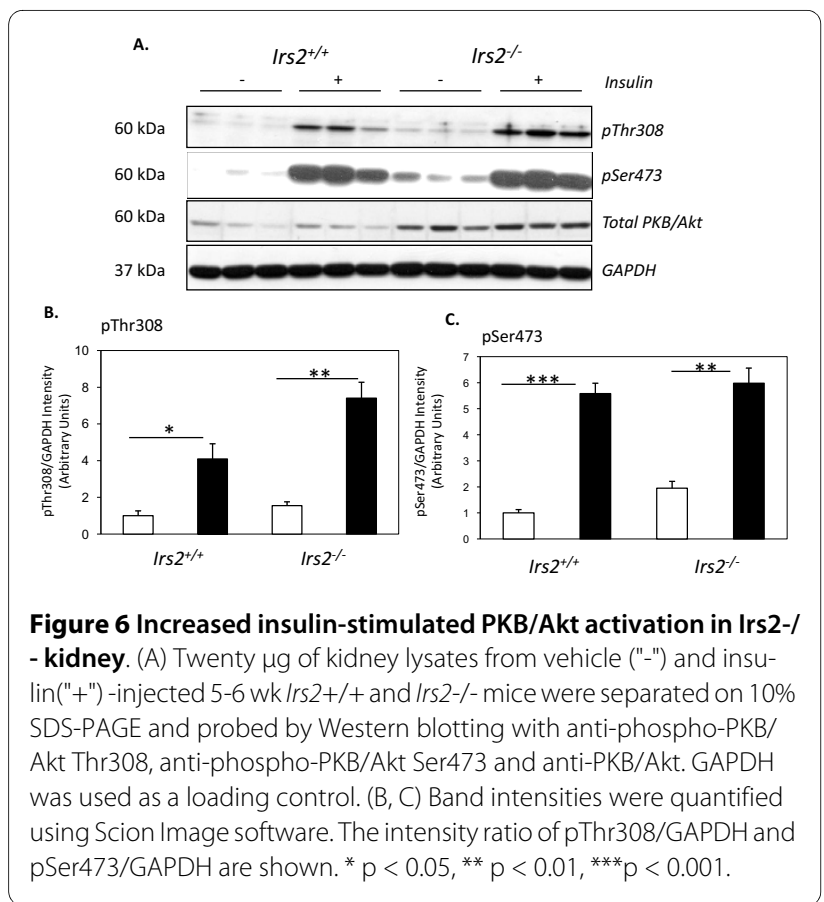

ever, a number of additional bands were detected with both phospho- and total GSK3 $\beta$ antibodies in Irs $2^{-1-}$ kidney extracts compared to wild-type, in both vehicle and insulin-stimulated mice (Fig. 7A). These data suggest that increased $\mathrm{PKB} / \mathrm{Akt}$ activation triggers hyperphosphorylation and inactivation of GSK3 $\beta$ in kidney. Consistent with this hypothesis, levels of $\beta$-catenin, a protein targeted by GSK3 $\beta$ for degradation, were markedly elevated in Irs $2^{-/}$kidney compared to controls (Fig. 7B, C). However, despite increased accumulation of $\beta$-catenin, no

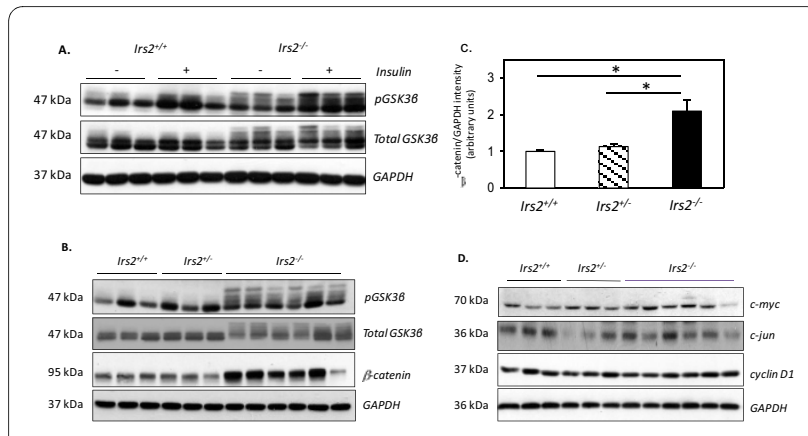

Figure 7 Altered GSK3 $\beta / \beta$-catenin signalling is evident in Irs $2^{-1-}$ mouse kidney. (A). Twenty $\mu \mathrm{g}$ of kidney protein lysates from Irs $2+/+$ and Irs2-/- mice injected with insulin were probed by Western blotting with the indicated antibodies. (B) Twenty $\mu \mathrm{g}$ of kidney protein lysates from female Irs2 $2^{+/+}(n=3)$, Irs2 $2^{+/}(n=3)$ and $\operatorname{Irs} 2^{-1-}(n=6)$ mice were probed with the indicated antibodies. GAPDH was used as loading control. (C) Band intensities were quantified using Scion Image software. The intensity ratio of $\beta$-catenin/GAPDH is shown. $p^{*}<0.05$. (D) Twenty $\mu \mathrm{g}$ of kidney protein lysates from $\operatorname{lrs} 2^{+/+}(n=3), \operatorname{Irs} 2^{+/-}(n=3)$ and $/ r s 2^{-1-}(n=6)$ mice were probed with anti-c-myc and anti-cyclin D1 antibodies. major changes in the expression of $\beta$-catenin targets $\mathrm{c}$ myc, c-jun and cyclin D1 were evident in Irs $2^{-/}$kidneys (Fig. 7D).

\section{Deletion of Irs2 causes kidney-specific increases in YAP expression and phosphorylation}

The Hippo-YAP pathway has shown to be crucial in cellular processes that increase mammalian organ size [30-32]. YAP is a transcriptional co-activator that is phosphorylated by kinase cascades such as Hippo/Mst1, leading to cytoplasmic localisation and inhibition of transcription $[32,33]$. Levels of total YAP were almost undetectable in kidney extracts of adult wild-type mice, but were significantly elevated in Irs $2^{-/-}$kidney compared to controls (Fig. 8A). Importantly, levels of YAP phosphorylation on the inhibitory site Ser127 were also increased in the absence of Irs2 (Fig. 8A). Previous data have suggested that PKB/ Akt may phosphorylate YAP, inhibiting its function [33]. In our study, insulin treatment had little effect on YAP phosphorylation in either wild-type and Irs2 $2^{-/}$kidney (Fig. 8B). No changes in YAP levels or phosphorylation were detected in other mouse tissues (data not shown). These data suggest that deletion of Irs 2 causes increased expression of the transcriptional co-activator YAP in kidney, which is immediately inactivated by phosphorylation, preventing potential YAP-induced increases in kidney size.

\section{Discussion}

IRS2 is a fundamental element in normal insulin and IGF-1 signalling, regulating glucose metabolism, brain growth, ovarian development and retinal photoreceptor

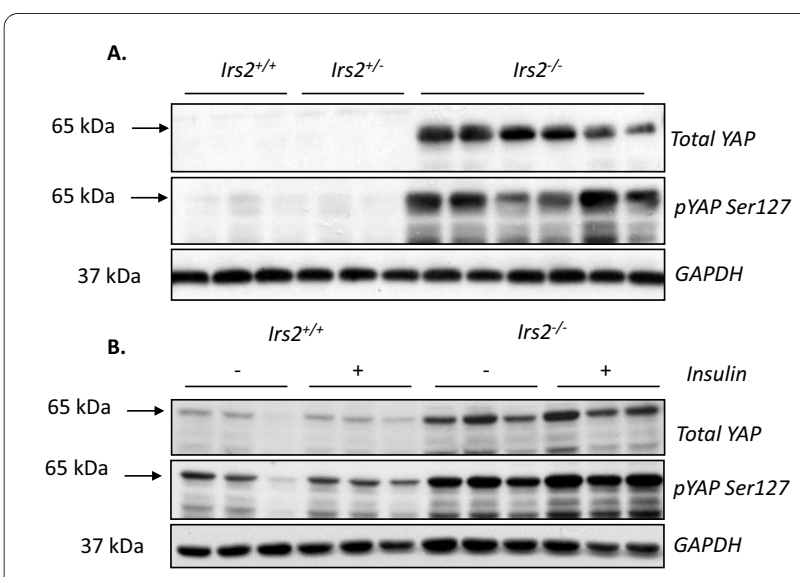

Figure 8 Phosphorylated and total YAP levels are markedly elevated in $/ r s 2^{-/-}$mouse kidney. (A) Twenty $\mu \mathrm{g}$ of kidney protein lysates from Irs2 $2^{+/+}(n=3)$, Irs2 $2^{+-}(n=3)$ and $/ r s 2^{-1-}(n=6)$ mice probed by Western blotting as indicated. (B) Six 5-6 wk female $/ \mathrm{rs} 2^{+/+}$and $/ r s 2^{-1-}$ mice were injected with insulin as indicated in Materials and Methods. Twenty $\mu \mathrm{g}$ of kidney protein lysates were probed as in (A). GAPDH was used as a loading control. 
apoptosis $[7,9,16,17,34]$. Defects in insulin signalling may contribute to diabetic kidney disease [25]. Our data identify a novel role for IRS2 in renal development and in the regulation of PKB/Akt/GSK3 $\beta$ and Hippo/YAP signalling in the kidney.

Defects in organ growth and development have been reported due to Irs2 gene deletion [16,17], with IRS1 playing a more dominant role in somatic growth compared to IRS2 [5-7]. Expression of IRS2 can be detected in renal cortex at E14.5, with minimal IRS1 and IRS3 detecetd at the same developmental time-point http:// www.eurexpress.org. Smaller kidneys were evident in Irs2 $2^{-/}$mice as early as postnatal day 5 (Fig. 2, 3), and kidney-to-body weight ratio increased more rapidly between postnatal day 5 and 12 in Irs2 $\%$ mice compared to wildtype, suggestive of catch-up growth in these animals (Fig. $3 C)$. However, this increased rate of growth was not sustained, and the kidney size defect did not recover as Irs $2^{-1}$ - mice aged. Interestingly, it has been reported that kidney and brain from $\operatorname{Irs} 1^{-1-}$ mice exhibited proportionately smaller weight reductions than the decrease in body weight [35], as opposed to larger kidney/organ-to-body weight ratio reduction observed in Irs $2^{-1-}$ mice. These data emphasise the predominant role of IRS2 rather that IRS1 in determining the growth of organs such as kidney and brain.

Despite decreased kidney size in Irs $2^{-/-}$mice, no major morphological changes or reduction in nephron density were detected, apart from slight compensatory glomerular hypertrophy. These results add to previous knockout studies which demonstrated that insulin/IGF-1 signalling pathway is not essential for renal morphogenesis, but may be important for overall organ growth [13-15].

The kidney-specific upregulation of PKB $\beta /$ Akt2 in Irs21 - mice is interesting based on the overall similarity of $\mathrm{PKB} /$ Akt isoforms, and previous data demonstrating a degree of redundancy within the PKB/Akt family [36]. Mice lacking Rictor, a key element of the TORC2 complex shown to phosphorylate PKB/Akt on Ser473 [37], develop increased organ size, including kidney [38]. The higher basal level of Ser473 phosphorylation seen in Irs2/- kidney suggests that higher TORC2 activity may contribute to reduced kidney size in the absence of IRS2. Experiments carried out by Zheng and colleagues identified that deletion of Irs 2 attenuated insulin stimulated bicarbonate absorption in isolated renal proximal tubules [24]. Of note, these authors detected a decrease in PKB/ Akt phosphorylation on Ser473 with no apparent change in $\mathrm{PKB} /$ Akt expression in kidney cortex of $\operatorname{Irs} 2^{-/}$mice (Fig. 6A, C[24]). The divergence between these observations and our data presented here may be explained by the fact that our study examined whole kidney lysates rather than isolated, cultured renal cortex slices. In con- trast to Zheng et al who examined Ser473 phosphorylation alone, the increase in $\mathrm{PKB} / \mathrm{Akt}$ phosphorylation was mainly detected on Thr308 in our experiments, and was supported by increased GSK3 $\beta$ phosphorylation on Ser9 (Fig. 6, 7).

The specific increase in $\mathrm{PKB} \beta /$ Akt2 protein (but not mRNA) suggests increased translation of PKB $\beta / A k t 2$ mRNA, or that posttranslational processes leading to PKB $\beta /$ Akt2 degradation are absent in the Irs2-/- kidney. This novel finding also suggests that this process is specific for the PKB $\beta /$ Akt2 isoform. This increase in expression, together with increased $\mathrm{PKB} /$ Akt phosphorlyation in the basal state may represent a compensatory mechanism resulting from the loss of IRS2, to enhance growth factor signalling in an effort to overcome defects in kidney growth during development. Importantly, these data imply that, contrary to the predicted cellular effects, loss of IRS2 somehow enhances, rather than inhibits PKB/Akt activation in the kidney. The precise molecular consequences of Irs 2 deletion in kidney cells remain to be determined.

GSK3 $\beta$ is directly inactivated downstream of $\mathrm{PKB} / \mathrm{Akt}$ via phosphorylation on Ser9 $[39,40]$. Hyperphosphorylation of GSK3 $\beta$ was detected in Irs2 $2^{-/}$kidney but not in liver or brain (Fig. 7). The "laddering" of GSK3 $\beta$ bands reactive with the phospho-Ser9 antibody, together with a decrease in the intensity of the GSK3 $\beta$ band at $47 \mathrm{kDa}$ (c.f. Fig. 7B) suggest that deletion of Irs2 causes PKB/Akt phosphorylation-dependent decreases in GSK3 $\beta$ activity. The accumulation of $\beta$-catenin (a GSK3 $\beta$ target) in the kidney of Irs $2^{-/}$mice (Fig 7B, C) suggests that increased phosphorylation of GSK3 $\beta$ leads to reduced GSK3 $\beta$ kinase activity in the kidney, facilitating $\beta$-catenin accumulation. This increase in $\beta$-catenin was not detected in other tissues; again suggesting that defects in PKB/Akt/ GSK3 $\beta / \beta$-catenin pathway is kidney specific in Irs2 $2^{-1-}$ mice. Active $\beta$-catenin binds to the TCF/Lef family of transcription factors [41] and serves as a co-activator to stimulate the transcription of genes such as cyclin D1 and c-myc $[42,43]$, which drive cell proliferation. However, protein levels of these $\beta$-catenin targets were not significantly altered in Irs $2^{-1-}$ kidney versus controls (Fig. 7D). Thus, increased cellular $\beta$-catenin levels do not appear to be sufficient to increase protein targets in Irs $2^{-/-}$kidney. It remains to be determined if changes in $\beta$-catenin levels alter its transcriptional activity during a period of defective embryonic kidney growth during development. Significantly, insulin-stimulated PKB/Akt activation was not decreased in Irs2-/- kidney at 5-6 wk (Fig. 6), and no changes in basal PKB/Akt/GSK3 $\beta$ signalling were detected in 5-6 wk Irs2-/- liver, where profound insulin resistance was previously reported (9). We therefore hypothesise that signalling changes reported here occur as a direct result of Irs2 deletion in kidney, and not as a 
result of insulin resistance. Analysis of PKB/Akt signalling at earlier time-points will help clarify these issues.

Several studies have clearly established that Hippo/ Mst1 pathway is critically involved in regulating organ growth [30-32]. In mammals, the Mst1/LATS/Mob1/YAP pathway plays a key role in restricting organ size by controlling both cell proliferation and apoptosis [44-46]. The final component of this pathway, YAP [47], is a potent growth promoter, and overexpression of YAP in the liver leads to organ enlargement [30,31]. YAP is inhibited by the Hippo pathway via phosphorylation on Ser127, leading to its cytoplasmic translocation and retention [32]. YAP levels were markedly elevated in Irs $2^{-/}$kidney compared to wild-type controls (Fig. 8A, B) Even though levels of YAP were higher in Irs2- $2^{-1}$ kidney, an increase in YAP phosphorylation on Ser127 was also evident, suggesting that immediate inactivation and nuclear export of YAP may occur in Irs2-/- kidney cells, preventing increased kidney growth. Preliminary data from our laboratory suggests that levels of active Mst1, the upstream kinase responsible for YAP phosphorylation on Ser127, are also elevated in Irs2 $2^{-/}$kidney. Consistent with these findings, protein levels of YAP downstream targets, Ecadherin and survivin did not change significantly in Irs2 1- kidney (data not shown). Therefore, similar to increased $\beta$-catenin, the accumulation of YAP in adult kidney may represent a compensatory mechanism for reduced kidney size in Irs $2^{-1-}$ mice. Ultimately, this compensatory response is ineffective due to rapid Ser127 phosphorylation and therefore inactivation of YAP. Thus, we hypothesise that reduced kidney size in Irs2-/- may trigger changes in GSK3 $\beta$ and YAP signalling that ultimately fail to overcome the growth defect in kidney.

\section{Conclusions}

In summary, we have established that mice lacking Irs2 display defects in kidney growth and PKB/Akt/GSK3 $\beta$ signalling. It is clear that the integration of many signalling pathways is required to regulate normal organ development. Irs2 gene deletion results in decreased kidney size and our observations suggest that specific signalling changes in the PKB/Akt and YAP pathway occur in Irs2-I - kidney. Future experiments will strive to identify the organ-specific growth control pathways that are relevant to kidney development in the Irs2 $2^{-/}$mouse.

\section{Methods}

\section{Experimental Animals}

All mouse experiments were carried out in accordance with the European Communities Council Directive (86/ 609/EEC). All mouse handling was performed by licensed technicians in the University College Dublin Biomedical Facility and was performed with the appropriate govern- mental and institutional ethical and legal approval and licenses. Experimental animals were generated by crossing Irs $2^{+/}$mice on a mixed genetic background $(\mathrm{C} 57 \mathrm{Bl} / 6$ $\times 129 \mathrm{sv})$. Genotyping was performed using DNA extracted from ear punches as described [9]. Anaesthesia and perioperative analgesia were used to maintain animal well-being throughout the experiments.

\section{In vivo manipulations}

All biochemical analysis was carried out according to Animal Models of Diabetic Complications Consortium, http://www.amdcc.org. Body weight was assessed biweekly until time of harvest. For insulin injections, groups of $I r s 2^{+/+}$and Irs2 $2^{-/}$mice were starved overnight and injected intraperitoneally (i.p.) with $5 \mathrm{U}$ human insulin (Humulin S, Eli Lilly and Co.) or saline vehicle for 30 min, after which mice were sacrificed by cervical dislocation and tissues harvested.

\section{Tissue/sample preparation}

The left kidney was ligated, removed and snap-frozen for protein and RNA extraction. Images were captured by thawing whole kidneys from both wild-type and Irs2-/mice (stored in RNAlater) and photographing on a glass slide. Perfusion-fixation of the right kidney was performed using non-fixative sterile normal saline $(\mathrm{pH}$ 7.4) for $5 \mathrm{~min}$, followed by $4 \%(\mathrm{w} / \mathrm{v})$ paraformaldehyde $(\mathrm{pH}$ 7.4) for $5 \mathrm{~min}$. The perfused right kidney was then removed and submersed in $4 \%$ paraformaldehyde for $24 \mathrm{~h}$ at RT. Kidneys were then paraffin embedded, cut at $3 \mu \mathrm{m}$ thickness and stained with haematoxylin eosin staining, Masson's Trichrome, periodic acid-Schiff and Picrosirius Red. Slides were scanned at $40 \times$ magnification using a ScanScope XT slide scanner (Aperio Technologies). Stained sections were scored independently (single blinded) by pathologists at the Department of Pathology, University Medical Center Utrecht, Netherlands. For calculation of glomerular number, each kidney was divided in 4 parts of equal thickness, of which the central two sections were embedded on successive non-adjacent cutsurfaces. Regions of the renal cortex were selected and the number of glomeruli counted in each square. This was repeated for 3 sections per kidney in 3 mice from 5-6 wk male Irs $2^{+/+}$and Irs2 $2^{-/}$groups. Glomeruli number was then normalised to sectional area in each group.

\section{IRS2/IRS1 RNA measurements}

Total RNA was extracted from cells and mouse tissues using Trizol (R) Reagent from Invitrogen. RNA from tissues was further purified using RNeasy columns (Qiagen). Reverse transcription reactions were performed using $1 \mu \mathrm{g}$ of RNA and Superscript ${ }^{\mathrm{mi}}$ II (Invitrogen). One $\mu l$ of synthesised cDNA was then used for semi-qauntitative and TaqMan PCR to amplifiy either IRS1 or IRS2. 
Oligonucleotides for semiquantitative PCR were as described (Withers et al 1998) and for TaqMan were purchased from Applied Biosystems (IRS2, Mm03038438_m1; IRS1 Mm00439720_s1). 18S was run as a normalisation control and the $\Delta \Delta \mathrm{Ct}$ method was used to calculate fold-change in RNA levels for each gene.

\section{Protein extraction, immmunoblotting and immunoprecipitation}

Both kidney tissue and cultured cells were lysed in RIPA buffer exactly as previously described [29]. Antibodies at the following dilutions were used: IRS-2 (1:500 generated in-house, Prof. Morris White), IRS-2 (Millipore, used for immunoprecipitation), polyclonal pAkt Ser473 (1:1000, Cell Signaling), pAkt Thr 308 (1:1000, Cell Signaling), pGSK-3 $\beta$ Ser9 (1:1000, Cell Signaling), total GSK-3 $\beta$ (1:1000, Cell Signaling), $\beta$-catenin (1:1000, BD Biosciences), total YAP (1:1000, Cell Signaling), pYAP Ser127 (1:1000, Cell Signaling), isoform specific PKB/Akt antibodies PKB $\alpha$ (1:500), PKB $\beta$ (1:500), PKB $(1: 5000)$ were a generous gift from Dr. Brian Hemmings, Friedrich Miescher Institute, Basel, Switzerland, total PKB/Akt (1:1000, Cell Signaling), GAPDH (1:5000, Cell Signaling), $\beta$-actin (1:25,000, Sigma). Reactive bands were revealed using HRP-coupled secondary antibodies and enhanced chemiluminescence reagents (Santa Cruz Biotechnology) and X-ray film.

Immunoprecipitation was carried out to detect IRS2 expression in the kidney. Kidneys were lysed as described above. Supernatants containing $1 \mathrm{mg}$ of protein lysate were pre-cleared with $20 \mu \mathrm{l}$ of a $50 \%$ slurry of protein-A/ G-Sepharose (Pierce) for $60 \mathrm{~min}$ at $4^{\circ} \mathrm{C}$ and incubated overnight with $5 \mu \mathrm{l}(5 \mu \mathrm{g})$ anti-IRS2 antibody (Millipore). Immune complexes were collected with $20 \mu \mathrm{l}$ of a $50 \%$ slurry of protein-A/G-Sepharose and resolved on a 7.5\% SDS-PAGE as described above.

\section{Statistical analysis}

All data were expressed as mean +/- SEM. Statistical analysis was carried out using InStat software. Student's unpaired t-test or analysis of variance (ANOVA) with post hoc Tukey-Kramer Multiple Comparison test was used, with a difference of $\mathrm{p}<0.05$ considered significant.

\section{Additional material}

Additional file 1 Elevated IRS1 gene expression in the kidneys of male 13-14 wk Irs2-/-diabetic mice. Compensatory changes in kidney IRS1 in the absence of IRS2.

Additional file 2 Reduced kidney size is evident in Irs2-/- kidneys compared to wild-type at $\mathbf{1 2}$ days of age. Kidney size is reduced in Irs2-/mice at $12 \mathrm{~d}$ of age.

Additional file 3 Irs 2 deletion does not significantly alter gross kidney structure. Histology of Irs2-/- kidneys showing no significant changes in morphology.
Additional file 4 Irs2 $2^{-/}$mice have reduced glomerular number but normal nephron density. No major changes in glomerular density in Irs2-/ -kidneys

Additional file 5 Kidney: body weight ratio is decreased in Irs2--mice. Kidney weights and kidney: body weight ratios in male and female mice at 13-14 wk.

\section{Authors' contributions}

RC carried out the experiments presented, MS provided insulin-stimulated kidneys for pilot analysis, RG performed histological scoring of kidney sections, FM provided expert advice and MFW provided Irs2+/- mice, antibody reagents and expert advice. DPB performed some experiments and wrote the final manuscript. All authors read and approved the final manuscript.

\section{Acknowledgements}

We thank Alfie Redmond, Stephen Morris, Joe Mooney and colleagues in the UCD Biomedical Facility for superb animal technical support. Sarah Roxburgh provided advice in renal phenotyping of diabetic mice. Expert histology support was provided by Dionne van der Giezen (Utrecht University Medical Centre), George Keating (UCD Conway Institute) and Brendan Tobin (Mater Misericordiae University Hospital, Dublin). Janet McCormick was essential for Aperio analysis. We are grateful to Brian Hemmings, Friedrich Miescher Institute for the gift of PKB/Akt isoform-specific antibodies. We thank Dr. James Murray (Queen's University Belfast) for the generous gift of survivin and cyclin D1 antibodies. Input from Prof. Jordan Kreidberg at the revision stage of this manuscript is gratefully acknowledged. Colleagues in the UCD Diabetes Research Centre are gratefully acknowledged for helpful discussions. This project was supported by the Mouse Metabolic Phenotyping Core, Vanderbilt University Medical Center, USA (DK59637). This work was supported by an EMBARK Initiative IRSCET scholarship to R.C. Both D.B. and F.M. are supported by Science Foundation Ireland.

\section{Author Details}

1 UCD Diabetes Research Centre, UCD Conway Institute, School of Medicine and Medical Science, University College Dublin, Belfield Dublin 4, Ireland, 2UCD Conway Institute, School of Biomolecular and Biomedical Science, University College Dublin, Belfield Dublin 4, Ireland, ${ }^{3}$ Centre for Vision and Vascular Science, School of Medicine, Dentistry and Biomedical Science, Queen's University Belfast, Belfast BT12 6BA, Northern Ireland, UK, ${ }^{4}$ Howard Hughes Medical Institute, Division of Endocrinology, Children's Hospital Boston, Harvard Medical School, Boston, MA 02115, USA and ${ }^{5}$ Department of Pathology, University Medical Center Utrecht, Heidelberglaan 100, 3584 CX Utrecht, The Netherlands

Received: 11 November 2009 Accepted: 6 July 2010

Published: 6 July 2010

\section{References}

1. Sun XJ, Rothenberg P, Kahn CR, Backer JM, Araki E, Wilden PA, Cahill DA, Goldstein BJ, White MF: Structure of the insulin receptor substrate IRS-1 defines a unique signal transduction protein. Nature 1991, 352:73-7.

2. White MF, Kahn CR: The insulin signaling system. J Biol Chem 1994, 269:1-4.

3. Nandi A, Kitamura Y, Kahn CR, Accili D: Mouse models of insulin resistance. Physio/ Rev 2004, 84:623-47.

4. Sun XJ, Wang LM, Zhang Y, Yenush L, Myers MG Jr, Glasheen E, Lane WS, Pierce JH, White MF: Role of IRS-2 in insulin and cytokine signalling. Nature 1995, 377:173-7.

5. Araki E, Lipes MA, Patti ME, Bruning JC, Haag B, Johnson RS, Kahn CR: Alternative pathway of insulin signalling in mice with targeted disruption of the IRS-1 gene. Nature 1994, 372:186-90

6. Tamemoto H, Kadowaki T, Tobe K, Yagi T, Sakura H, Hayakawa T, Terauchi Y, Ueki K, Kaburagi Y, Satoh S, et al.: Insulin resistance and growth retardation in mice lacking insulin receptor substrate-1. Nature 1994, 372:182-6.

7. Withers DJ, Burks DJ, Towery HH, Altamuro SL, Flint CL, White MF: Irs-2 coordinates Igf-1 receptor-mediated beta-cell development and peripheral insulin signalling. Nat Genet 1999, 23:32-40.

8. Kubota N, Tobe K, Terauchi $Y$, Eto $K$, Yamauchi T, Suzuki R, Tsubamoto $Y$, Komeda K, Nakano R, Miki H, et al: Disruption of insulin receptor 
substrate 2 causes type 2 diabetes because of liver insulin resistance and lack of compensatory beta-cell hyperplasia. Diabetes 2000 49:1880-9.

9. Withers DJ, Gutierrez JS, Towery H, Burks DJ, Ren JM, Previs S, Zhang Y, Bernal D, Pons S, Shulman Gl, et al.: Disruption of IRS-2 causes type 2 diabetes in mice. Nature 1998, 391:900-4.

10. Conlon I, Raff M: Size control in animal development. Cell 1999, 96:235-44.

11. Han VK, Carter AM: Control of growth and development of the fetoplacental unit. Curr Opin Pharmacol 2001, 1:632-40.

12. Okada S, Kopchick JJ: Biological effects of growth hormone and its antagonist. Trends Mol Med 2001, 7:126-32.

13. Accili D, Drago J, Lee EJ, Johnson MD, Cool MH, Salvatore P, Asico LD, Jose PA, Taylor SI, Westphal H: Early neonatal death in mice homozygous for a null allele of the insulin receptor gene. Nat Genet 1996, 12:106-9.

14. Liu JP, Baker J, Perkins AS, Robertson EJ, Efstratiadis A: Mice carrying null mutations of the genes encoding insulin-like growth factor I (Igf-1) and type 1 IGF receptor (Igf1r). Cell 1993, 75:59-72.

15. Louvi A, Accili D, Efstratiadis A: Growth-promoting interaction of IGF-II with the insulin receptor during mouse embryonic development. Dev Biol 1997, 189:33-48.

16. Yi X, Schubert M, Peachey NS, Suzuma K, Burks DJ, Kushner JA, Suzuma I, Cahill C, Flint CL, Dow MA, et al:: Insulin receptor substrate 2 is essentia for maturation and survival of photoreceptor cells. J Neurosci 2005, 25:1240-8.

17. Schubert M, Brazil DP, Burks DJ, Kushner JA, Ye J, Flint CL, Farhang-Fallah J, Dikkes $P$, Warot XM, Rio C, et al: Insulin receptor substrate-2 deficiency impairs brain growth and promotes tau phosphorylation. J Neurosci 2003, 23:7084-92.

18. Feraille $E$, Carranza ML, Rousselot $M$, Favre H: Insulin enhances sodium sensitivity of Na-K-ATPase in isolated rat proximal convoluted tubule. Am J Physiol 1994, 267:F55-62.

19. Ito O, Kondo Y, Takahashi N, Kudo K, Igarashi Y, Omata K, Imai Y, Abe K Insulin stimulates $\mathrm{NaCl}$ transport in isolated perfused MTAL of Henle's loop of rabbit kidney. Am J Physiol 1994, 267:F265-70.

20. Klisic J, Hu MC, Nief V, Reyes L, Fuster D, Moe OW, Ambuhl PM: Insulin activates $\mathrm{Na}(+) / \mathrm{H}(+)$ exchanger 3: biphasic response and glucocorticoid dependence. Am J Physiol Renal Physiol 2002, 283:F532-9.

21. Marunaka Y, Hagiwara N, Tohda H: Insulin activates single amilorideblockable Na channels in a distal nephron cell line (A6). Am J Physiol 1992, 263:F392-400

22. Nakamura R, Emmanouel DS, Katz Al: Insulin binding sites in various segments of the rabbit nephron. J Clin Invest 1983, 72:388-92.

23. Ruiz OS, Qiu YY, Cardoso LR, Arruda JA: Regulation of the renal Na-HCO3 cotransporter: IX. Modulation by insulin, epidermal growth factor and carbachol. Regul Pept 1998, 77:155-61.

24. Zheng Y, Yamada H, Sakamoto K, Horita S, Kunimi M, Endo Y, Li Y, Tobe K Terauchi $Y$, Kadowaki T, et al.: Roles of insulin receptor substrates in insulin-induced stimulation of renal proximal bicarbonate absorption. J Am Soc Nephrol 2005, 16:2288-95.

25. Raz I, Wexler I, Weiss O, Flyvbjerg A, Segev Y, Rauchwerger A, Raz G, Khamaisi M: Role of insulin and the IGF system in renal hypertrophy in diabetic Psammomys obesus (sand rat). Nephrol Dial Transplant 2003, 18:1293-8.

26. Bakin AV, Tomlinson AK, Bhowmick NA, Moses HL, Arteaga CL: Phosphatidylinositol 3-kinase function is required for transforming growth factor beta-mediated epithelial to mesenchymal transition and cell migration. J Biol Chem 2000, 275:36803-10.

27. Piek E, Moustakas A, Kurisaki A, Heldin CH, ten Dijke P: TGF-(beta) type I receptor/ALK-5 and Smad proteins mediate epithelial to mesenchymal transdifferentiation in NMUMG breast epithelial cells. Book TGF-(beta) type / receptor/ALK-5 and Smad proteins mediate epithelial to mesenchymal transdifferentiation in NMuMG breast epithelial cells 1999, 112:4557-4568.

28. Cho HJ, Baek KE, Saika S, Jeong MJ, Yoo J: Snail is required for transforming growth factor-beta-induced epithelial-mesenchymal transition by activating PI3 kinase/Akt signal pathway. Biochem Biophys Res Commun 2007, 353:337-43.

29. Kattla JJ, Carew RM, Heljic M, Godson C, Brazil DP: Protein kinase B/Akt activity is involved in renal TGF \{beta\}-1 driven epithelial-mesenchymal transition in vitro and in vivo. Am J Physiol Renal Physiol 2008.
30. Camargo FD, Gokhale S, Johnnidis JB, Fu D, Bell GW, Jaenisch R, Brummelkamp TR: YAP1 increases organ size and expands undifferentiated progenitor cells. Curr Biol 2007, 17:2054-60.

31. Dong J, Feldmann G, Huang J, S Wu, Zhang N, Comerford SA, Gayyed MF, Anders RA, Maitra A, Pan D: Elucidation of a universal size-control mechanism in Drosophila and mammals. Cell 2007, 130:1120-33.

32. Zhao B, Wei X, Li W, Udan RS, Yang Q, Kim J, Xie J, Ikenoue T, Yu J, Li L, et al:: Inactivation of YAP oncoprotein by the Hippo pathway is involved in cell contact inhibition and tissue growth control. Genes Dev 2007 21:2747-61

33. Basu S, Totty NF, Irwin MS, Sudol M, Downward J: Akt phosphorylates the Yes-associated protein, YAP, to induce interaction with 14-3-3 and attenuation of p73-mediated apoptosis. Mol Cell 2003, 11:11-23.

34. Burks DJ, Font de Mora J, Schubert M, Withers DJ, Myers MG, Towery HH Altamuro SL, Flint CL, White MF: IRS-2 pathways integrate female reproduction and energy homeostasis. Nature 2000, 407:377-82

35. Pete G, Fuller CR, Oldham JM, Smith DR, D'Ercole AJ, Kahn CR, Lund PK Postnatal growth responses to insulin-like growth factor I in insulin receptor substrate-1-deficient mice. Endocrinology 1999, 140:5478-87.

36. Koseoglu S, Lu Z, Kumar C, Kirschmeier P, Zou J: AKT1, AKT2 and AKT3dependent cell survival is cell line-specific and knockdown of all three isoforms selectively induces apoptosis in 20 human tumor cell lines. Cancer Biol Ther 2007, 6:755-62.

37. Sarbassov DD, Guertin DA, SM Ali, Sabatini DM: Phosphorylation and regulation of Akt/PKB by the rictor-mTOR complex. Science 2005, 307:1098-101

38. Cybulski N, Polak P, Auwerx J, Rüegg MA, Hall MN: mTOR complex 2 in adipose tissue negatively controls whole-body growth. Proc Nat/ Acad SciUSA 2009, 106:9902-7.

39. Cross DA, Alessi DR, Cohen P, Andjelkovich M, Hemmings BA: Inhibition of glycogen synthase kinase-3 by insulin mediated by protein kinase $B$. Nature 1995, 378:785-9.

40. Cohen P, Frame S: The renaissance of GSK3. Nat Rev Mol Cell Biol 2001 , 2:769-76

41. Behrens J, von Kries JP, Kuhl M, Bruhn L, Wedlich D, Grosschedl R, Birchmeier W: Functional interaction of beta-catenin with the transcription factor LEF-1. Nature 1996, 382:638-42.

42. He TC, Sparks AB, Rago C, Hermeking H, Zawel L, da Costa LT, Morin PJ, Vogelstein B, Kinzler KW: Identification of c-MYC as a target of the APC pathway. Science 1998, 281:1509-12.

43. Tetsu O, McCormick F: Beta-catenin regulates expression of cyclin D1 in colon carcinoma cells. Nature 1999, 398:422-6.

44. Edgar BA: From cell structure to transcription: Hippo forges a new path. Cell 2006, 124:267-73.

45. Harvey K, Tapon N: The Salvador-Warts-Hippo pathway - an emerging tumour-suppressor network. Nat Rev Cancer 2007, 7:182-91.

46. Pan D: Hippo signaling in organ size control. Genes Dev 2007, 21:886-97.

47. Yagi R, Chen LF, Shigesada K, Murakami Y, Ito Y: A WW domaincontaining yes-associated protein (YAP) is a novel transcriptional coactivator. Embo J 1999, 18:2551-62.

doi: 10.1186/1471-213X-10-73

Cite this article as: Carew et al., Deletion of Irs2 causes reduced kidney size in mice: role for inhibition of GSK3?? BMC Developmental Biology 2010, 10:73 